\title{
Trends in social inequalities in male mortality, 2001-08. Intercensal estimates for England and Wales
}

Ann Langford and Brian Johnson, Office for National Statistics

\section{Abstract}

\section{Background}

This article presents estimates of mortality rates for men of working age by the National Statistics Socio-economic Classification (NS-SEC). Previously it has been possible to produce such mortality rates only at the time of a census, when populations are enumerated by occupation and NS-SEC. This is the first time that annual intercensal estimates have been produced, enabling the measurement of health inequalities by NS-SEC for the period 2001-08.

\section{Methods}

The Labour Force Survey (LFS) was used to provide population denominators by age and NS-SEC for men aged 25-64 for each year between 2001 and 2008. Numbers of deaths for the corresponding period were obtained from death registrations, and age-standardised mortality rates were derived. A number of measures of the inequality in mortality rates across socio-economic classes were compared.

\section{Results}

There has been a steady decrease in mortality rates for all NS-SEC classes over the period, 2001-08. Mortality rates for the 'Routine' class declined on average by around 11 deaths per 100,000 population per year, almost double that of the 'Higher managerial and professional' class. Absolute differences between the mortality of the least and most advantaged classes showed a small decline based on three different measures. Relative differences, however, increased over this period. In 2001 the mortality rate of those in routine and manual occupations was 2.0 times that of those in managerial and professional occupations. In 2008 that ratio had risen to 2.3. This pattern of declining absolute but rising relative inequalities is a well known phenomenon in the context of declining overall mortality rates. 


\section{Conclusions}

The results presented suggest that annual trends in inequalities in mortality at the national level can be effectively monitored using LFS-based measures. This would complement the current measures that are based on area of residence rather than the socio-economic position of the individual.

\section{Contents}

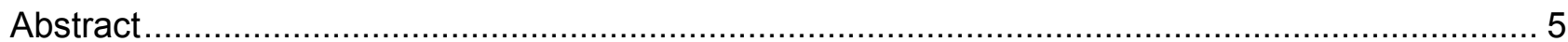

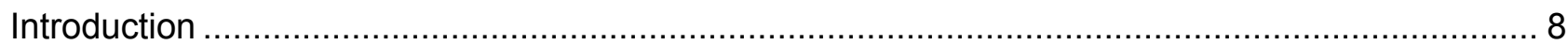

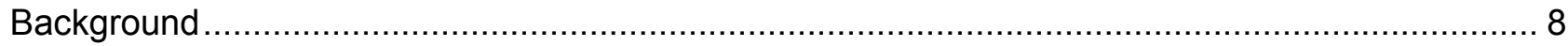

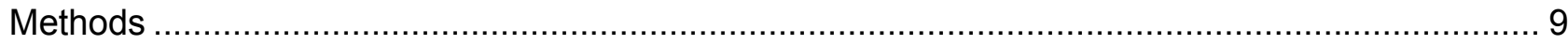

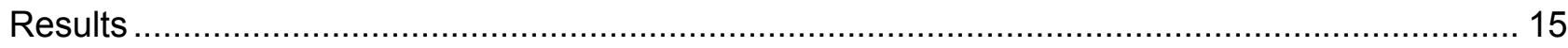

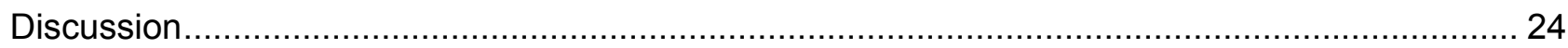

Conclusions

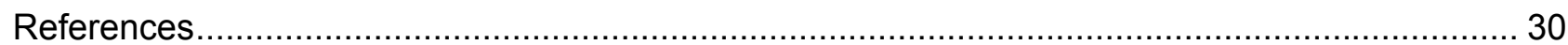




\section{List of Figures}

Figure 1 Age-standardised mortality rates by NS-SEC for 2001-08, men aged 25-64.

Figure 2 Measures of absolute inequalities in mortality rates of NS-SEC classes by year, men aged 25-64

Figure 3 Measures of relative inequalities in mortality rates of NS-SEC classes by year, men aged 25-64. All measures indexed at $2001=100$.

Figure 4 Three year simple moving averages of age-standardised mortality rates by NS-SEC, men 25-64, 2001-08.

Figure 5 Comparison of the age-standardised mortality rate for the Routine class with allcause all-age mortality of the 'Spearhead' areas.

Figure 6 Comparison of the aggregated model-based mortality rate with all-cause all-age mortality for England.

Figure 7 Comparison of age-standardised mortality rates by NS-SEC for 2001, 2002 and 2003 with those produced using denominators based on the 2001 Census.

\section{List of Tables}

Table 1 Age-standardised mortality rates and annual changes in mortality rates by sevenclass NS-SEC for 2001-08, men aged 25-64

Table 2 Age-standardised mortality rates and annual changes in mortality rates by threeclass NS-SEC for 2001-08, men aged 25-64

Table 3 Estimated annual decrease in mortality rate by NS-SEC and year, men aged 25-64

Table 4 Measures of absolute inequalities in mortality rates of NS-SEC classes by year, men aged $25-64$.

Table 5 Measures of relative inequalities in mortality rates of NS-SEC classes by year, men aged $25-64$ 


\section{Introduction}

The presence of inequalities in mortality according to socio-economic position is well known, and has been the subject of a number of studies (The Black Report 1980, The Acheson Report 1998). The recent strategic review of health inequalities (The Marmot Review 2010) concluded that a social gradient in health persists and that action should focus on reducing it.

The need to tackle these inequalities gives rise to the need for reliable and timely measures to evaluate progress. While a number of measures exist and have been used by the Department of Health to monitor progress in reducing health inequalities, there is currently no measure based on the socio-economic position of individuals which is capable of annual updating.

This article presents, for men aged 25-64, estimated annual mortality rates by the National Statistics Socio-economic Classification (NS-SEC) for the years 2001 to 2008, along with a number of measures of inequality derived from those rates. It has not previously been possible to produce such annual mortality estimates, since the estimates of the population at risk by social classification were available only from the census. This article uses a methodology developed by the Office for National Statistics (ONS) that uses the Labour Force Survey (LFS) to provide annual estimates of the population at risk by NS-SEC (Johnson and Langford 2010). Analysis of trends in inequality over the eight-year period allows the assessment of this measure for monitoring health inequalities over time.

\section{Background}

The study of inequalities in mortality rates has a long history. The influential Black Report highlighted inequalities in mortality by social class in the 1980s. Subsequent authors have found that although overall mortality rates have fallen, relative inequalities have been increasing. For instance, Drever and Bunting (1997) looked at trends in male mortality from the 1970s to the 1990s and found that although there had been declines in mortality for each social class, there had been a relative widening in the differential between the least and the most disadvantaged. White et al. (2003), studying trends in social class differences in mortality over the period 1986 to 2000 , reached a similar conclusion. Davey Smith et al. (2002), using area-based deprivation deciles as an indicator of socio-economic position, also came to the conclusion that relative health inequalities increased over the 1990s.

The Acheson report (1998) highlighted widening social inequalities and informed government strategy as outlined in 'Tackling Health Inequalities: A Programme for action' (Department of Health 2003). As part of this strategy a national public service agreement (PSA) was introduced which aimed, by 2010 , to reduce inequalities in health outcomes by 10 per cent as measured by infant mortality and life expectancy at birth. The life expectancy target was underpinned by a more detailed objective which was to reduce, by at least 10 per cent, the gap in life expectancy at birth between the fifth of local authorities with the worst health and deprivation indicators (the Spearhead Group) and the population as a whole.

A 2006-08 policy and target update (Department of Health 2009) concluded that although life expectancy had improved across the board, the gap between the Spearhead Group and England as a whole was now 7 per cent wider than the baseline. However the report also pointed out that 
for males, some progress had been made, as the gap in all-age all-cause mortality had reduced from 142.4 deaths per 100,000 population in $1995-97$ to 126.3 per 100,000 population in $2006-08$.

The recent Strategic Review of Health Inequalities (The Marmot Review 2010), commissioned by the Department of Health, concluded that a social gradient in health remained and that action to reduce these inequalities was required across all the social determinants of health. It also proposed that progress should in future be monitored nationally against three main aspirational targets, including one on health outcomes as measured by life expectancy, healthy life expectancy and wellbeing.

This article aims to contribute to the debate on health inequalities by presenting, for the first time, annual mortality rate data for the period 2001-08 classified by the NS-SEC. These rates are used to produce a number of absolute and relative indicators which could be used to monitor health inequalities over time. These indicators would measure inequalities between individuals in different socio-economic groups. In this way they would differ from and complement previous target measures which are geographically based.

\section{Methods}

This section describes the NS-SEC in more detail, specifies the data sources used and describes the analytical approach adopted in this article.

\section{The National Statistics Socio-economic Classification}

The conceptual basis for the NS-SEC, as developed by Rose and Pevalin (2003), is the structure of employment relations operating in modern developed economies. Occupations are differentiated in terms of reward mechanisms, promotion prospects, autonomy and job security. The most advantaged NS-SEC classes (Higher managerial and professional), typically exhibit personalised reward structures, have good opportunities for advancement, relatively high levels of autonomy within the job, and are relatively secure. These attributes tend to be reversed for the most disadvantaged class (Routine).

Box 1 shows the NS-SEC analytic seven-class schema used in this analysis, and provides examples of the occupations included in each class. The classes 1 to 7 are referred to as 'analytic' classes, while those with no occupation (for instance the long-term unemployed or full-time students) are referred to as a 'residual' class.

There is also an aggregated three-class version of the NS-SEC where classes 1 and 2 are defined as 'Managerial and professional', classes 3 and 4 are defined as 'Intermediate' and classes 5, 6 and 7 are defined as 'Routine and manual' .

The NS-SEC category is derived from an individual's occupation and employment status and the size of their organisation. Since size of organisation is not collected on the death register, a version of NS-SEC is used which is derived from occupation and employment status alone. This is known as 'reduced NS-SEC' and differs in terms of its typical distribution among NS-SEC classes by less than 3 per cent. Reduced NS-SEC is used throughout the following analysis. 


\section{Box 1 National Statistics Socio-economic Classification analytic classes}

Analytic class

$1 \quad$ Higher managerial and professional

2 Lower managerial and professional

3 Intermediate

$4 \quad$ Small employers and own account workers

$5 \quad$ Lower supervisory and technical

6 Semi-routine

$7 \quad$ Routine
Examples of occupations included

Senior officials in national and local government; directors and chief executives of major organisations, civil engineers, medical practitioners, IT strategy and planning professionals, legal professionals, architects

Teachers in primary and secondary schools, quantity surveyors, public service administrative professionals, social workers, nurses, IT technicians

Non-commissioned Officers (NCOs) and other ranks in the Armed Forces, graphic designers, medical and dental technicians, local government clerical officers, counter clerks

Hairdressing and beauty salon proprietors, shopkeepers, dispensing opticians in private practice, farmers, self-employed taxi drivers

Bakers and flour confectioners, screen-printers, plumbers, electricians and motor mechanics employed by others, gardeners, rail transport operatives

Pest control officers, clothing cutters, traffic wardens, scaffolders, assemblers of vehicles, farm workers, veterinary nurses and assistants, shelf fillers

Hairdressing employees, floral arrangers, sewing machinists, van, bus and coach drivers, labourers, hotel porters, bar staff, cleaners and domestics, road sweepers, car park attendants

ONS(2007) 


\section{Data sources for analysis}

The following data sources for England and Wales were used in the analysis:

- $\quad$ Counts of deaths by NS-SEC, extracted from death registration data

- $\quad$ The LFS-based populations derived from the weighted LFS datasets

- $\quad$ ONS mid-year population estimates by age group, used in the analysis as control totals

The LFS, which is designed to provide information on the UK labour market, collects detailed data on occupation for a sample of approximately 60,000 households in the UK each quarter.

Respondents are interviewed five times, at 13-week intervals. Interviews are carried out mostly by telephone, although the first interview is face-to-face. LFS data are available at national, regional and local authority levels. Results from the survey are weighted to ONS estimates of the private household population (ONS 2009).

\section{Analytical approach}

In this study, estimates of mortality rates by NS-SEC were produced using deaths by five-year agebands extracted from the death registrations (numerators) and population estimates based on the LFS (denominators).

The numerators were adjusted to correct for a misallocation of deaths identified by White et al. (2007). This study found that a number of deaths were likely to have been misclassified as NSSEC class 3 (Intermediate) rather than NS-SEC class 2 (Lower managerial and professional). This was because some death registration entries did not record that the individual concerned had a supervisory role. Examination of the ONS Longitudinal Study (LS) revealed that there was evidence from the census that these individuals had indeed been supervisors, and therefore should have been classified as NS-SEC class 2. The proportions suggested in White et al. (2007) were used to correct for this misallocation.

The population figures (denominators) were obtained using the LFS and adjusted to compensate for the effect of health selection. Many authors (Fox et al. 1985, Blane et al. 1993) have commented on this phenomenon which is a particular problem for mortality analysis. The hypothesis is that health status influences socio-economic status, leading to a selection out of the labour market of those in poor health, which may have a disproportionate effect across the 'analytic' NS-SEC class denominators (those relating to specific groups of occupations).

The process of adjustment for health selection follows that described in Johnson and Langford (2010). In brief, the process has two phases. Firstly, an estimate was made of the total number of people currently unclassified by NS-SEC that should be redistributed to the 'analytic' NS-SEC classes. This was done by calculating the difference between the total LFS population and the ONS mid-year population estimates for each specific calendar year and five-year age-band. The percentages that should remain unclassified were estimated using Table 1 in White et al. (2007), and adjusted by growth rates in LFS populations for subsequent years. These two estimates were 
then combined to estimate the number of people currently unclassified that should be redistributed across 'analytic' NS-SEC classes.

Secondly, the distribution by NS-SEC to be applied in the reallocation was based on Table 2 in White et al. (2007). This table compares the distribution by NS-SEC of LS members produced using 2001 occupational details with a distribution where 1991 occupational details have been used if 2001 details were missing. The difference between these two distributions was used to determine the reallocation of those persons deemed to be affected by health selection.

Using adjusted death and population estimates, age-specific mortality rates were then calculated as well as age-standardised mortality rates for each class and year. The European standard population was used for standardisation.

Estimates of the variances were calculated taking into account the variance of the death counts, the sampling variance of the LFS population estimates and the additional variation associated with the health selection adjustments. Confidence intervals and standard statistical tests were carried out assuming normality of the estimated rates.

\section{Outcome measures}

For each year age-standardised rates for each NS-SEC class were calculated. To examine inequalities, two types of indicators were considered, absolute and relative. Absolute indicators measure the difference between the least and most advantaged in terms of the number of deaths per person year. Relative indicators measure inequality as a ratio of the mortality rate of the least to the most advantaged. An illustration of the difference between absolute and relative measures is given in Box 2.

As a result of the different potential interpretation of absolute and relative measures of inequalities, it was decided to produce indicators of both absolute and relative inequality. Three indicators of absolute inequality were calculated. The first indicator was simply the difference in mortality rates between the least and most advantaged NS-SEC classes, using the broad three-class schema. Thus this indicator was the difference between the mortality rates for the 'Managerial and professional' class and the 'Routine and manual' class. The second indicator adopted a similar approach, but was based on the more detailed seven-class version of NS-SEC, and was therefore the difference between the mortality rates of the 'Routine' class and the 'Higher managerial and professional' class (NS-SEC class 7 and 1). 


\section{Box 2 The difference between absolute and relative measures}

To illustrate the difference between the two types of measures consider the following hypothetical example where the mortality rate for the 'Routine' class (NS-SEC class 7) is 500 deaths per 100,000 person years, and the mortality rate for the 'Higher managerial and professional' class (NS-SEC class 1 ) is 100 deaths per 100,000 years. Imagine that the rates change to 450 deaths and 75 deaths respectively. In absolute terms of deaths per 100,000 person years, the gap between the most and least advantaged classes is 400 in the first instance (500-100) and 375 in the second instance (450-75). This implies that the inequality, in terms of the absolute number of deaths involved, has reduced.

In the same hypothetical example, however, the deaths in the 'Routine' class are five times as high (500/100) as those in the more advantaged class. In the second instance the relative inequalities imply that mortality rates of the disadvantaged are now six times as high (450/75). So inequality in relative terms has become larger.

In this example the reduction in mortality rates for the more advantaged class, the 'Higher managerial and professional' class has been small in terms of the number of deaths (25 deaths) compared to the reduction achieved in the 'Routine' class (50 deaths). But because the more advantaged class starts at a much lower level the percentage improvement is large (25 per cent) compared to the percentage improvement in the 'Routine' class (10 per cent). Thus because the more advantaged class is at a lower level it is much harder to achieve similar percentage reductions in the more disadvantaged class, and hence maintain the relative gap.

Some authors (Mustard and Etches 2003, Wagstaff et al. 1991) have criticised these types of indicators as being based solely on the extremes of the socio-economic scale and recommend indicators that use all of the available data. The third indicator, the slope index of inequality (SII), uses all of the available data to model the difference between mortality rates of those with the hypothetically lowest and highest socio-economic position. (More detail of the calculation method is given in Box 3) All three indicators are measures of absolute inequality and are calibrated in terms of differences in the numbers of deaths per head of population among the NS-SEC classes. 
Three indicators of relative mortality were also calculated. The first was the ratio of the mortality rate of the least to the most advantaged NS-SEC class, using the broad three-class schema. Thus the first indicator was the ratio of the mortality rates of the 'Routine and manual' class to that of the 'Managerial and professional' class. The second indicator was similar, but based on the more detailed version of NS-SEC and was the ratio of the mortality rates of the 'Routine' class and the 'Higher managerial and professional' class (NS-SEC class 7 and 1). The third indicator is an analogous measure to the SII, the relative index of inequality (RII). This indicator takes into account the intervening classes, in addition to the most and least advantaged classes. (More detail of the calculation method is given in Box 3 ) All three indicators are relative measures of inequality and compare the position of the more disadvantaged groups in terms of the more advantaged group.

\section{Box 3 The calculation of slope and relative index of inequality (SII and RII )}

These indices were calculated following the method described in Sergeant and Firth (2006)

The socio-economic groups were ordered, from lowest to highest socio-economic status. The fraction of the population in class $i$ or lower was calculated $\left(c_{i}\right)$, thus $c_{i}$ represents the cumulative proportion in class $\mathrm{i}$ or lower. Each group was then assigned a median social rank

$$
\mathrm{x}=\left(\mathrm{c}_{\mathrm{i}}+\mathrm{c}_{\mathrm{i}-1}\right) / 2
$$

The mortality rate for each class, $\mathrm{y}$, was then regressed against the median social rank, using group population totals as weights, yielding a straight line estimate

$$
\mathrm{y}=\mathrm{a}+\mathrm{bx}
$$

The slope index of inequality (b) represents the difference in mortality rates between the highest and lowest on the socio-economic scale. (As calculated, $b$ is negative, but has been reported as positive for ease of presentation.) The RII was then calculated as $\mathrm{a} /(\mathrm{a}+\mathrm{b})$ and thus represents the ratio of mortality rates of the least advantaged to the most advantaged.

\section{Comparisons with other results}

The mortality rate of the most disadvantaged class, the 'Routine' class, was compared against statistics published by the Department of Health (2009) on the all-cause all-age mortality of the 'Spearhead' areas. Although covering different geographic areas and different ages, both measures attempt to capture the mortality experience of the most disadvantaged, and should therefore exhibit comparable behaviour over time. 
Another series, published by the Department of Health (2009), is the all-cause all-age mortality for England. This was compared with the aggregated all-class mortality rate based on the models used to construct the slope and relative index of inequality. Again the behaviour of these two series over time should be consistent, and should help validate both the underlying model and the results.

The final comparison made was between the results produced here for 2001-03 and those produced by White et al. (2007) where mortality rates were calculated using the Census 2001 data as the population denominator. The pattern of mortality over the socio-economic classes should be comparable.

\section{Results}

The age-standardised mortality rates for are displayed in Table 1, Table 2 and Figure 1.

Figure 1 demonstrates that for each class there has been a steady decrease in mortality rates over the period 2001-08. An estimate of the average annual improvement for each class was obtained by fitting a simple linear regression model against time for each class. Table 3 shows the average annual improvement (with standard errors) for each class.

The rate of decrease in terms of deaths per year was between four and eight deaths per 100,000 men aged 25-64 per year for all classes except the 'Routine' class where the improvement is of the order of 11 deaths per 100,000 per year, significantly higher than most other NS-SEC classes. This reduction equates to a total across all classes of just over 1000 fewer deaths per year in England and Wales, of which approximately 200 are of men in routine occupations.

\section{Figure 1 Age-standardised mortality rates by NS-SEC for 2001-08, men aged 25-64}

England and Wales

Rate per 100,000 person years

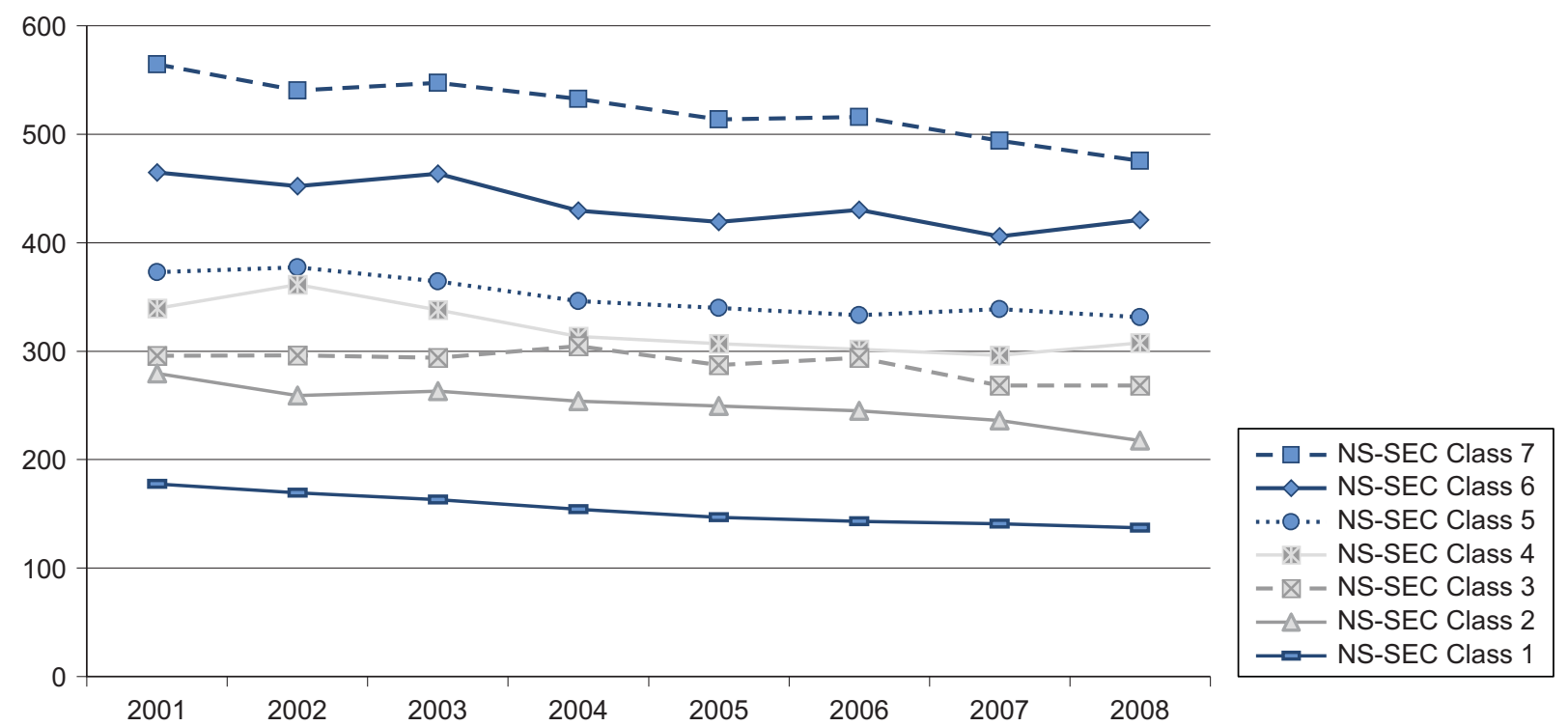




\section{Table $1 \quad$ Age-standardised mortality rates ${ }^{1}$ and annual changes ${ }^{2}$ in mortality rates by seven-class NS-SEC for 2001-08, men aged 25-64}

England and Wales

\begin{tabular}{|c|c|c|c|c|c|c|c|}
\hline & \multicolumn{7}{|c|}{ NS-SEC analytic class } \\
\hline & 1 & 2 & 3 & 4 & 5 & 6 & 7 \\
\hline 2001 & 178 & 280 & 296 & 339 & 373 & 465 & 564 \\
\hline 2002 & 169 & 259 & 296 & 362 & 377 & 452 & 541 \\
\hline change & -8 & -21 & 0 & 22 & 4 & -13 & -24 \\
\hline 2003 & 163 & 263 & 294 & 338 & 364 & 464 & 547 \\
\hline change & -6 & 4 & -2 & -24 & -13 & 12 & 7 \\
\hline 2004 & 154 & 254 & 305 & 313 & 346 & 430 & 533 \\
\hline change & -9 & -9 & 11 & -25 & -18 & -34 & -15 \\
\hline 2005 & 147 & 249 & 287 & 307 & 340 & 419 & 514 \\
\hline change & -8 & -4 & -17 & -7 & -7 & -10 & -19 \\
\hline 2006 & 143 & 245 & 294 & 302 & 333 & 430 & 516 \\
\hline change & -4 & -5 & 7 & -5 & -7 & 11 & 2 \\
\hline 2007 & 141 & 236 & 268 & 296 & 339 & 406 & 494 \\
\hline change & -2 & -9 & -26 & -6 & 6 & -25 & -22 \\
\hline 2008 & 137 & 217 & 268 & 307 & 331 & 421 & 476 \\
\hline change & -4 & -19 & 0 & 11 & -8 & 15 & -18 \\
\hline
\end{tabular}

Rates are statistically significantly higher than the previous year

Rates are statistically significantly lower than the previous year

1. Rates are directly standardised to the European standard population. Numerators and denominators have been adjusted as described in the article.

2. Change is the difference from the age-standardised mortality rate of the same NS-SEC class in the previous year. 


\section{Table 2 Age-standardised mortality rates ${ }^{1}$ and annual changes ${ }^{2}$ in mortality rates by three-class NS-SEC for 2001-08, men aged 25-64}

\section{NS-SEC analytic class}

Managerial and professional

232

217

$-15$

change

2003

change

2004

change

2005

change

2006

change

2007

change

2008

change

215

Intermediate

Routine and manual

328

466

345

456

17

$-10$

327

457

$-18$

1

\section{Rates are statistically significantly higher than the previous year}

Rates are statistically significantly lower than the previous year

1. Rates are directly standardised to the European standard population. Numerators and denominators have been adjusted as described in the article.

2. Change is the difference from the age-standardised mortality rate of the same NS-SEC class in the previous year. 


\section{Table $3 \quad$ Estimated annual decrease ${ }^{1}$ in mortality rate by NS-SEC and year, men aged 25-64}

Rate per 100,000

\begin{tabular}{llrr}
\hline & NS-SEC & $\begin{array}{c}\text { Estimated annual } \\
\text { decrease }\end{array}$ & Standard error \\
\hline 1 & Higher managerial and professional & -5.9 & 0.5 \\
2 & Lower managerial and professional & -7.2 & 0.9 \\
3 & Intermediate & -4.1 & 1.4 \\
4 & Self-employed and own-account & -7.9 & 2.1 \\
5 & Lower supervisory and technical & -6.9 & 1.1 \\
6 & Semi-routine & -7.7 & 1.8 \\
7 & Routine & -11.5 & 1.2 \\
\hline
\end{tabular}

1. Annual decrease estimated from a simple linear regression against time for the period 2001-08.

\section{Inequalities}

\section{Absolute measures}

Table 4 presents three measures of absolute inequality. The three measures are presented graphically in Figure 2, indexed to $2001=100$ to aid the comparison of trends.

\section{Table 4 Measures of absolute inequalities in mortality rates of NS- SEC classes by year, men aged 25-64}

Rate per 100,000

\begin{tabular}{lccc}
\hline & $\begin{array}{c}\text { Absolute difference of mortality rates } \\
\text { between 'Managerial and professional' } \\
\text { and 'Routine and manual' class }\end{array}$ & $\begin{array}{c}\text { Absolute difference of mortality } \\
\text { rates 'between 'Higher managerial and } \\
\text { professional' and the 'Routine' class }\end{array}$ & Slope index of inequality \\
\hline 2001 & 233 & 387 & 416 \\
2002 & 239 & 371 & 415 \\
2003 & 241 & 384 & 421 \\
2004 & 228 & 378 & 403 \\
2005 & 223 & 367 & 392 \\
2006 & 229 & 373 & 402 \\
2007 & 222 & 353 & 386 \\
2008 & 229 & 339 & 392 \\
\hline
\end{tabular}

1. Mortality rates are age-standardised to the European standard population. Numerators and denominators have been adjusted as described in the article. 
The variation in the measures is explained by the size of the groupings involved. The difference between the mortality rate of those in the 'Managerial and professional' class and those in the 'Routine and manual' class is based on the three-class NS-SEC schema, while the second indicator is based on a seven-class NS-SEC schema. Although the slope index of inequality is based on all the data, it models the difference between the hypothetically lowest and highest person on the socio-economic scale. As a result, this measure presents the difference between the theoretical extremes of the measure and thus will always be greater than those based on whole NS-SEC classes.

All three measures agree that, in terms of the absolute numbers of deaths per 100,000, inequalities decreased over the period. Figure 2 presents the three measures indexed to $2001=100$ to enable a visual comparison of the rates of decrease. The difference between those in higher managerial and professional occupations and those in routine occupations appears to be more volatile. This measure also shows the steepest decline, but this is mainly due to the behaviour of the series in 2008 (Table 1).

\section{Figure 2 Measures of absolute inequalities in mortality rates of NS- SEC classes by year, men aged 25-64}

England and Wales

Index: $2001=100$

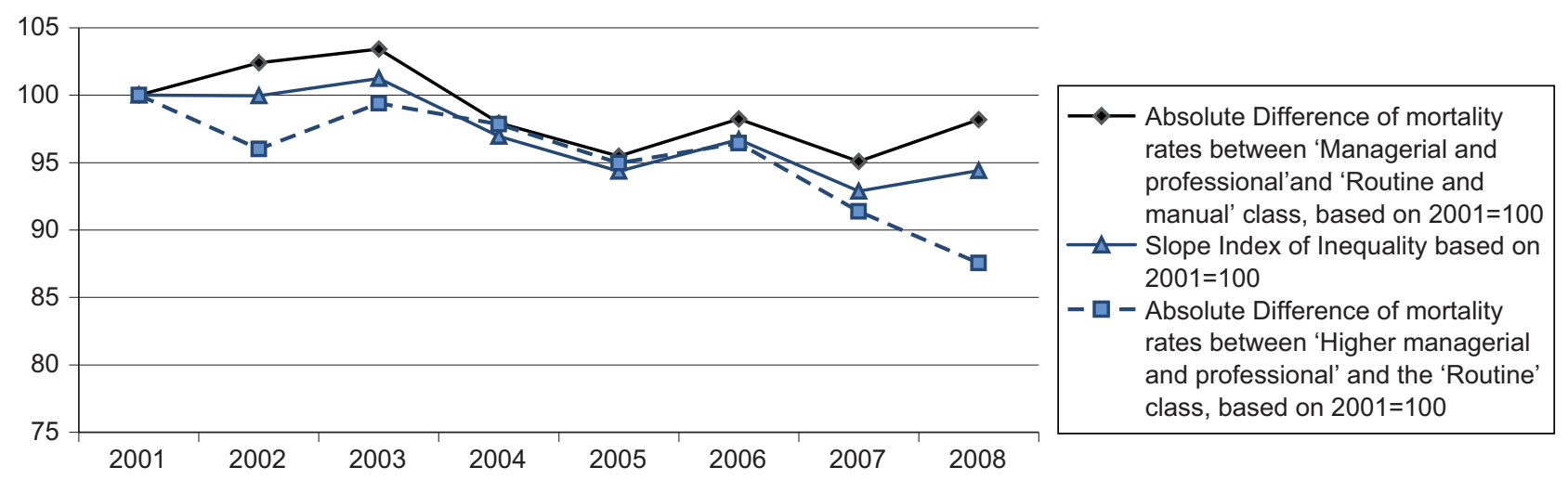

The absolute difference between the mortality rates of the 'Managerial and professional' class and those in 'Routine and manual' class, and the slope index of inequality both behave in a similar manner. The downward trend of the slope index of inequality is statistically significant, with the largest annual reductions occurring in 2004 and 2007.

\section{Relative measures}

Table 5 presents three measures of relative inequality. The three measures are presented graphically in Figure 3, indexed to $2001=100$ to aid the comparison of trends. 


\begin{tabular}{lccc} 
Table 5 & \multicolumn{3}{c}{$\begin{array}{l}\text { Measures of relative inequalities in mortality rates of NS- } \\
\text { SEC classes by year, men aged 25-64 }\end{array}$} \\
England and Wales & $\begin{array}{c}\text { Ratio of mortality rates' between } \\
\text { 'Managerial and professional' and } \\
\text { 'Routine and manual' class, based on } \\
\mathbf{2 0 0 1 = 1 0 0}\end{array}$ & $\begin{array}{c}\text { Ratio of mortality rates' between } \\
\text { 'Higher managerial and professional' } \\
\text { and the 'Routine' class, based on } \\
\mathbf{2 0 0 1}=100\end{array}$ & $\begin{array}{c}\text { Relative index of } \\
\text { inequality }\end{array}$ \\
\hline 2001 & 2.0 & 3.2 & 4.1 \\
2002 & 2.1 & 3.2 & 4.4 \\
2003 & 2.1 & 3.4 & 4.6 \\
2004 & 2.1 & 3.5 & 4.7 \\
2005 & 2.1 & 3.5 & 4.7 \\
2006 & 2.2 & 3.6 & 5.1 \\
2007 & 2.2 & 3.5 & 5.0 \\
2008 & 2.3 & 3.5 & 5.4 \\
\hline
\end{tabular}

1. Mortality rates are age-standardised to the European standard population. Numerators and denominators have been adjusted as described in the article.

Once again, the variation in the magnitude of the measures is explained by the size of the groupings involved. The ratio of the mortality rates of the 'Routine and manual' class to that of the 'Managerial and professional' class is based on the three-class NS-SEC schema. The second indicator is based on a seven-class NS-SEC schema. The third indicator uses all the data to model the difference between the hypothetically lowest and highest person on the socio-economic scale. As the size of the groups at the two extremes compared decreases, so the relative difference can be expected to increase.

All indicators agree on an increase in relative inequalities in the period. All show a statistically significant rise over the whole period. The pattern of the rises of the ratio of the mortality rates of the 'Routine and manual' class to that of the 'Managerial and professional' class is similar to the pattern of the relative index of inequality (Figure 3). Both show greater rises in inequalities in 200608 than in 2003-05. 


\section{Figure 3 Measures of relative inequalities in mortality rates of NS- SEC classes by year, men aged 25-64}

England and Wales

Index: $2001=100$

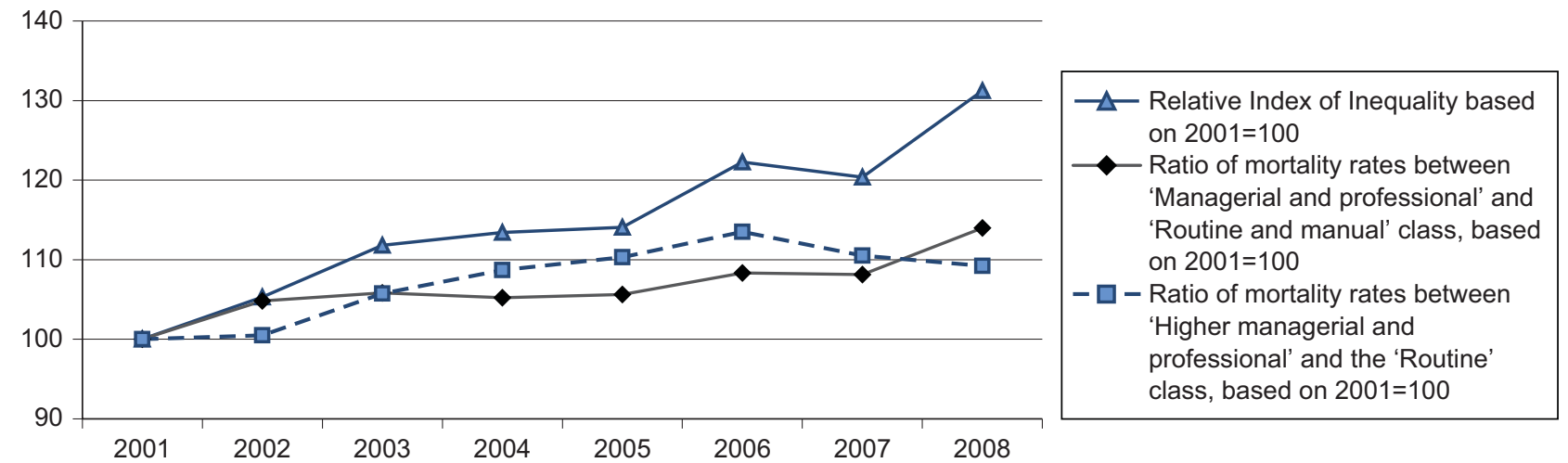

\section{Longer-term trends}

As an indication of longer-term trends, the mortality rates were smoothed by taking a simple rolling three-year moving average of the age-standardised mortality rates (Figure 4). All classes show a steady decline in mortality rates over the whole period.

\section{Comparison with other measures}

The results above can be compared with statistics published by the Department of Health (2009). For example Figure 5 shows the mortality rates of the 'Routine' class from the present study, and those of the Spearhead Group in England, indexed to 2001 for ease of comparison. Figure 6 shows the overall all-class mortality rate, as calculated from our results, against the male all-age all-cause mortality for England, again indexed to 2001=100. Both figures demonstrate that the changes observed over time in the mortality rates presented above are consistent with data published by the Department of Health to monitor the 2010 National Target (Department of Health 2009). 
Figure 4

Three year simple moving averages of age-standardised mortality rates ${ }^{1}$ by NS-SEC, men $25-64,2001-08$

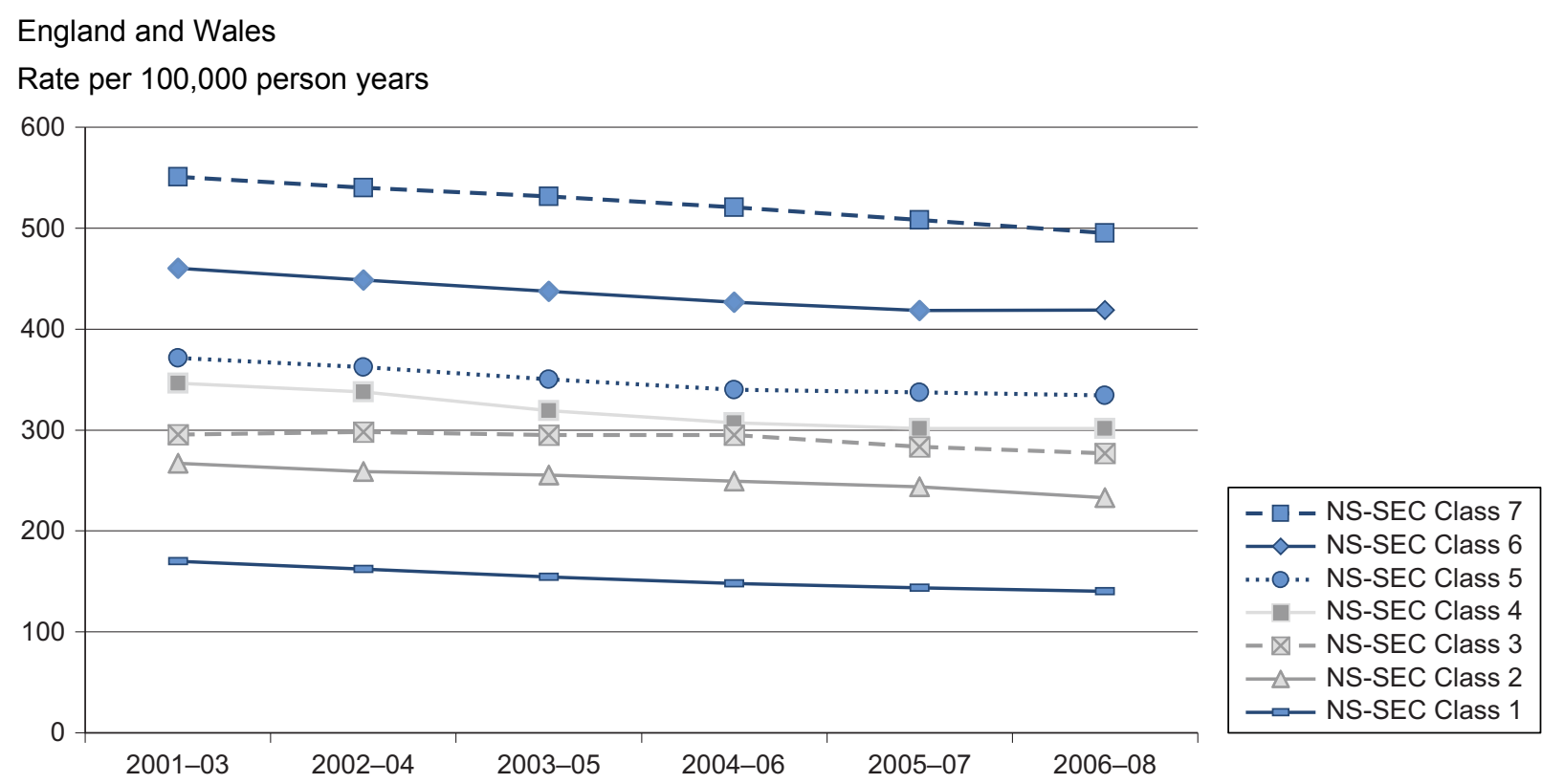

1. Rates are directly standardised to the European standard population. Numerators and denominators have been adjusted as described in the article. Moving averages calculated as the average of the three individual years.

\section{Figure 5 Comparison of the age-standardised mortality rate for the Routine class ${ }^{1}$ with all-cause all-age mortality of the 'Spearhead' areas ${ }^{2}$}

England and Wales

Index: $2001=100$

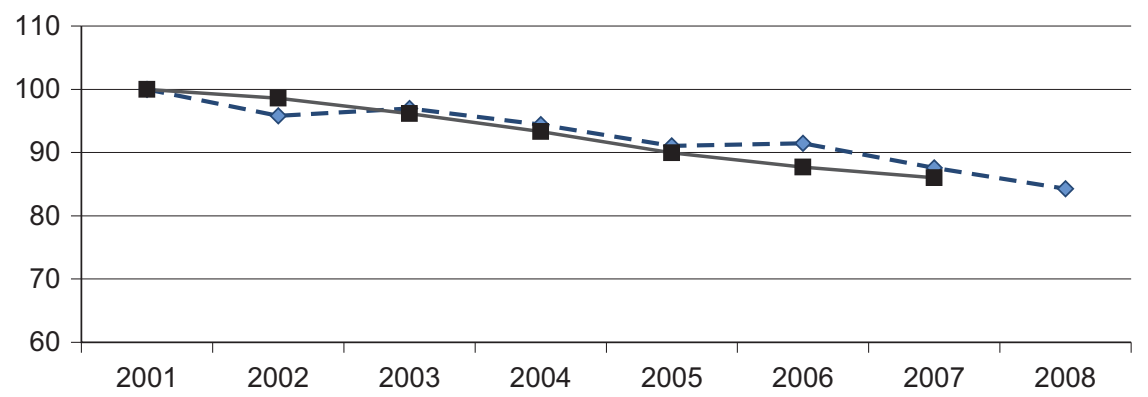

$-\diamond-$ Routine class mortality rate, based on $2001=100$

$\rightarrow$ All-cause all-age mortality rate for Spearhead areas, based on $2001=100$

1. Rates are directly standardised to the European standard population. Numerators and denominators have been adjusted as described in the article.

2. Three year centred averages as published in Department of Health (2009) 


\section{Figure 6 Comparison of the aggregated model-based mortality rate ${ }^{1}$ with all-cause all-age mortality for England ${ }^{2}$}

Index: $2001=100$

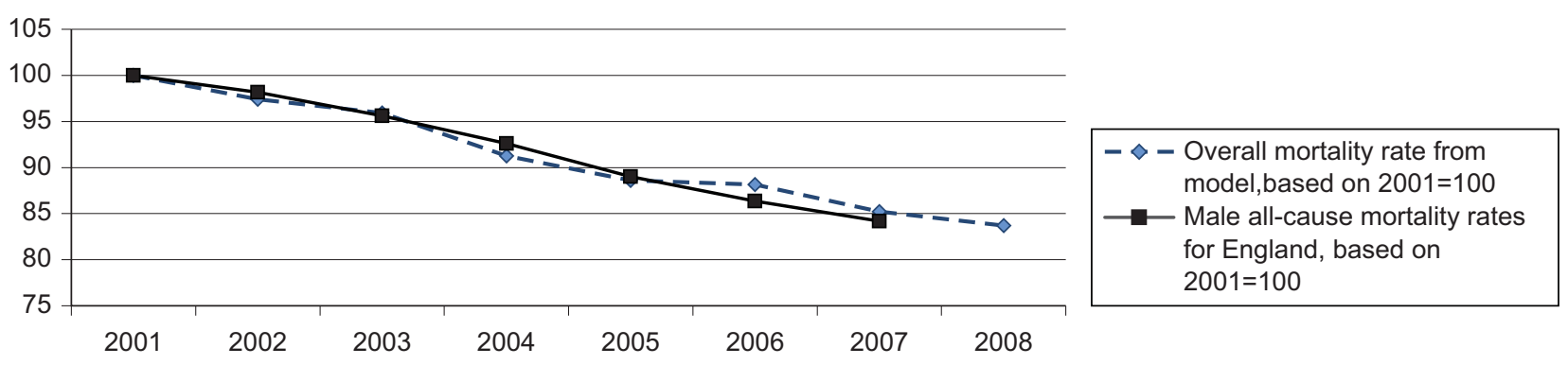

1. Overall mortality rates for all NS-SEC analytic classes, estimated from the weighted regression models used to calculate SII and RII.

2. Three year centred averages as published in Department of Health (2009)

The previous methodological paper (Johnson and Langford 2010) discussed the differences between the census and provisional estimates produced using the LFS. That study used the threeyear period 2001-03 as opposed to single years and concluded that there seemed to be a systematic pattern for the LFS-based estimates to underestimate mortality for the 'Higher managerial and professional' class and, to a lesser extent, the 'Semi-routine' class. That study also found a systematic overestimate for the self-employed (NS-SEC Class 4) relative to the censusbased estimates. Figure 7 compares the results of the current study for 2001, 2002 and 2003 with the census-based estimates for 2001-03. Mortality rates for the 'Higher managerial and professional' class were again lower than those produced based on the Census, and rates for the self-employed were higher for all three years. Thus the results presented here are similar to the census-based estimates, but there are some systematic differences. However, the relative ratios were very similar when based on the three-class NS-SEC schema. (2.0, 2.1, 2.1 for 2001-03 respectively, as compared to 2.0 for the census-based estimates). 
England and Wales

Rate per 100,000 person years

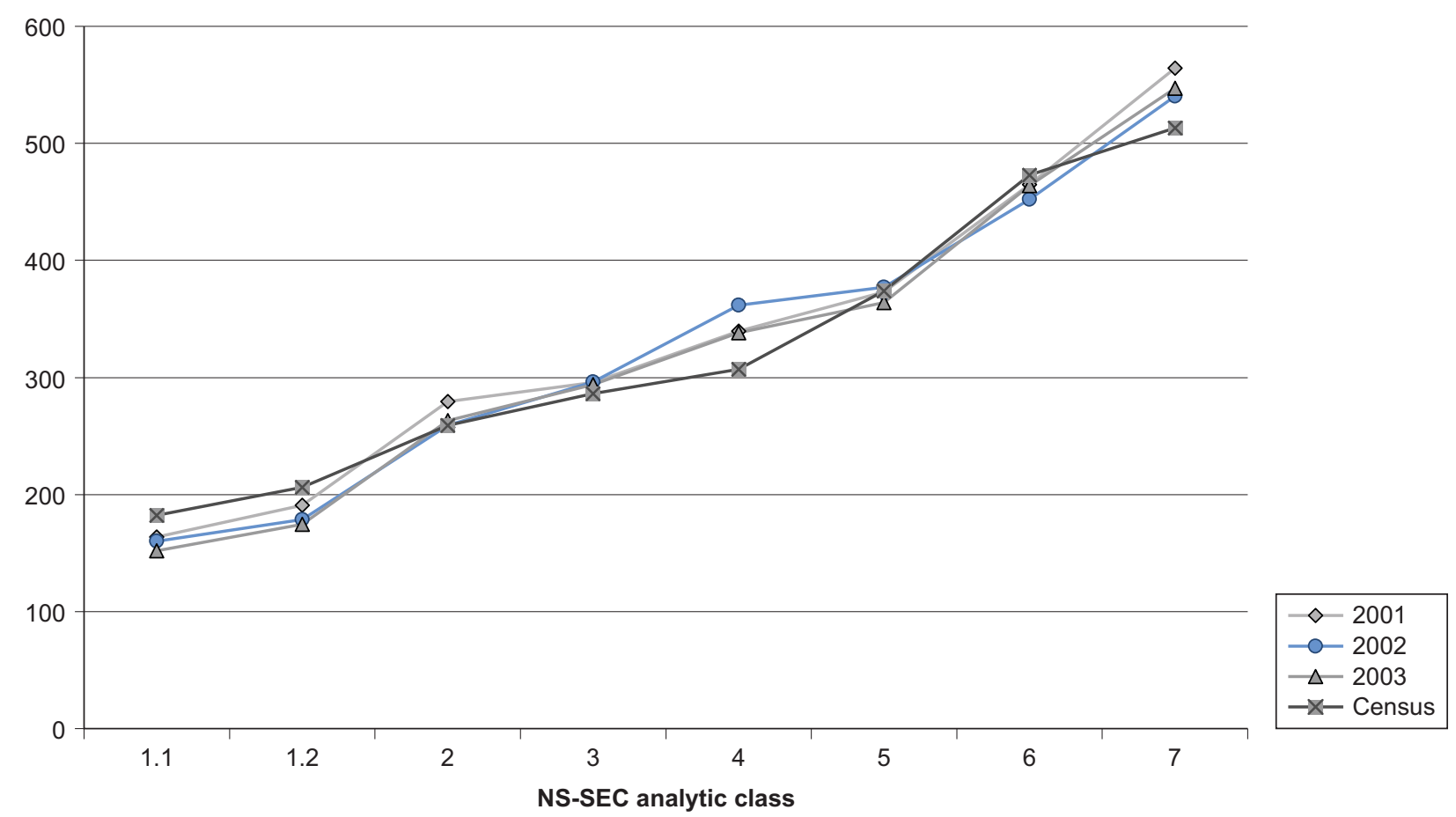

1. NS-SEC analytic class 1 has been broken down into its two component classes: 1.1 Higher managerial and 1.2 Higher professional

2. From White C et al. (2007)

\section{Discussion}

\section{Use of absolute and relative indexes for the measurement of inequality}

The results show that there has been a steady decrease in mortality rates for all classes over the period, 2001-08. In particular, the 'Routine' class experienced a reduction in mortality rate almost double that of those in the 'Higher managerial and professional' class. Absolute differences in mortality between classes (that is, the difference between the least and most advantaged as measured in the number of deaths per 100,000 person years) have shown a small decline. On the other hand, relative differences (that is the difference between the least and most advantaged expressed as a multiple of the mortality rate of the most advantaged) increased over this period.

The results presented here suggest that absolute and relative measures can and do move in opposite directions. This phenomenon has been discussed in the literature, although perhaps not sufficiently, given its importance.

Victora et al. (2000) stated that relative scales are more appropriate for the study of inequalities because they take into account baseline levels. They pointed out that the use of absolute measures will almost 'inevitably lead to an apparent reduction in equality gaps'. Fryers (2009) in a 
discussion paper for the Marmot Review also drew attention to the inadequacy of absolute measures when examining gaps between classes.

By contrast, both Mustard and Etches (2003) and Bartley (2004) suggested that, in terms of public health planning where the objective is to maximise the population impact of a health policy investment, it might be preferable to use absolute differences rather than relative differences. $A$ policy which achieves a large relative reduction in inequality, might only deliver a small difference in the overall number of lives saved. Bostrom \& Rosen (2003) have also pointed out that relative measures can be problematic. They quote the example of Sweden in a cross-sectional European comparison where, although the most disadvantaged had a lower mortality rate than in any other European country studied, the relative inequality was higher than in some other countries.

Scanlan (2000) argued that increasing relative inequalities are 'nearly inevitable' when overall mortality falls. The question of whether variations in relative measures are a mathematical artefact was addressed by Eikemo et al. (2009). They concluded that there was some empirical evidence that higher relative inequalities were associated with lower overall levels. Houweling et al. (2007), in a cross-national analysis of child health, also found that the magnitude of relative differences were empirically related to the overall level of the outcomes. However Houweling et al. (2007) also found that absolute inequalities tend to be low at both very high and very low overall levels. Thus it would appear that there is a strong association between low mortality rates and high relative inequalities, but it is not impossible to achieve a reduction in relative rates when overall mortality rates are falling.

Mackenbach and Kunst (1997) recommended that both types of indicators should be used to measure inequalities. Other authors (Houweling et al. 2007, Bostrom and Rosen 2003) concurred that both measures can be meaningful, but warned that the overall level of outcome must be taken into account. The Marmot Review (2010) also advocated using both type of measure, and warned of perverse incentives if a single indicator alone was used.

In summary, the choice of measure should depend upon the purpose and caution is required in the interpretation of both relative and absolute measures.

\section{'Range' or 'slope' measures?}

Another issue raised by these results concerns the question of whether to use simple measures of the 'range' between the extremes of the class distribution or so-called 'slope' measures which take into account the size and mortality rates of all classes but are consequently more complex.

Wagstaff et al. (1991) were unequivocal in their endorsement of 'slope' measures. Most other authors including The Marmot Review (2010) and Mackenbach and Kunst (1997) advocate the use of both 'simple' measures and slope or regression based ones. The latter state that: 'The study of socio-economic inequalities in health frequently aims at informing policy-makers who are quite right in preferring simple and straightforward measures. Nevertheless, it is true that the "range" measure ignores the experience of the in-between social groups and that the results of the easily comprehensible "range" measure should be checked against the results of...the regression-based effect indices'. This remains a sensible approach. 
Of the absolute and relative measures of inequality presented, those using the three-class version of NS-SEC are more stable than those using the seven-class. If a simple measure of inequality is required for annual comparisons it would appear that the indicators based on the three-class NSSEC should be recommended. If however policy-makers wish to concentrate on changes affecting the 'Routine' class in particular, this would suggest using the full range of NS-SEC.

\section{Suitability of the LFS-based measures for monitoring health inequalities}

Most high-level health inequalities targets have been set in terms of geographical areas rather than individual characteristics. For example, the Department of Health set its life expectancy targets based on the difference between the Spearhead local authorities and England as a whole. Areabased targets are subject to the 'ecological fallacy', whereby variations in deprivation among individuals within the deprived areas are ignored. Under such a system, an apparent improvement might be achieved by only the most affluent individuals within the target areas gaining benefit from a particular initiative, or by the movement of more and less advantaged individuals between areas. The reason that geographical measures are chosen is usually that individual characteristics such as NS-SEC are not available at the local level. The analysis presented here represents an attempt to use individual-based data, thus avoiding the ecological fallacy, albeit based on a sample of the population.

The overall interpretation of the indicators presented here would be similar to all-age all-cause mortality which is sometimes used as a proxy measure for the life expectancy target (Department of Health 2009). Figures 5 and 6 suggest that the 'Routine' class mortality rate has moved in line with that of the Spearhead areas and overall all-class mortality rate has had a similar trajectory to the all-cause all-age mortality rate.

The other high level monitoring tool for mortality in England based on individual records is the series showing trends in life expectancy by social class (ONS 2007). This used the ONS Longitudinal Study (LS) to produce life expectancies for five-year periods between 1972 and 2005. This has been the most useful long-term measure of life expectancy by social class for England and Wales, but is subject to a time-lag in the linkage of vital events data to the study. Therefore the proposed series based on the LFS would be as timely as any based on annual deaths and more timely than an LS based series.

The LFS based series, however, could not be used for monitoring local area changes in health inequalities below regional level. In the previous article in this series (Johnson and Langford 2010), a test was undertaken to determine whether use at local authority level would be feasible. It was concluded that the confidence intervals for a typical unitary authority would be approximately $+/-34$ per cent around the estimated mortality rate for a class - too great to be of use as a monitoring tool.

Finally, the purpose of any indicator should not be lost sight of. Fryers (2009) distinguished between health indicators and performance indicators. The former are metrics which describe the situation and allow the monitoring of whether things are improving or deteriorating, but may not be directly controllable by organisations seen as responsible for the target. Performance indicators describe how well or badly organisations have performed in delivering objectives. The measures described in this article are high-level health indicators and, as such, could be considered to be at 
least as useful as the current geographically based ones, provided they are used at national or regional level.

\section{Limitations of the analysis}

The results presented are dependent on the LFS as a source of population denominators and thus, any changes in LFS methodology over the time period could have affected the results. There have been changes in the LFS over the period studied. For instance, sample sizes have changed with boosts introduced for Wales in 2001, with further boosts for English urban areas introduced for 2004 and 2005. This later boost was not used in our analysis as the boost questionnaire did not include questions which allow the allocation of the reduced form of NS-SEC. Sample sizes themselves should not affect mortality rate estimates, but changes in response rates could introduce bias. The response rate on the LFS has changed from 69 per cent in 2001 to 60 per cent in the first quarter of 2008 with high refusal rates in London and in flats and 'mobile' accommodation (Barnes et al. 2008). However the weighting system corrects for non-response by local authority, age-group, sex and region and since 2007 uses a methodologically superior calibration weighting process (Thomas et al. 2008). The weights calculated in 2007 have been used throughout this analysis, so the results presented above should be consistent.

A number of other assumptions were made during the production of the population estimates. The principal ones were introduced as a result of the health selection adjustment, used to correct for the known bias in the assignment of populations to NS-SEC classes. These were:

- $\quad$ The percentage of those unallocated to an NS-SEC analytic class to be reallocated to an analytic class varies over time in proportion to the numbers in these categories computed using the LFS for the corresponding period

- The distribution across analytic classes of the reallocated population is in the same proportion over time as those derived from tables published in White et al. (2007). These redistributions are in the same proportions across all age groups

These adjustments are fully described in Johnson and Langford (2010). If the selection effect on the denominators is changing over time in its effect across the NS-SEC classes, then these assumptions may result in a degree of bias.

There is a case for not making these health selection adjustments. It could be argued that the yearto-year consistency of the LFS would best be maintained by using unadjusted population estimates. However health selection effects are well known, even in cross-sectional analyses, and to ignore them would invite a known bias.

Another assumption made was that those living in communal establishments and not counted by the LFS did not make a substantive difference in the distribution across NS-SEC analytic classes for men aged 25-64. This would appear reasonable, since deaths at communal establishments were only about two per cent of all deaths for men under age 65 and there was no identifiable pattern among analytic NS-SEC classes in the proportion of deaths which were at communal establishments (Johnson and Langford 2010). 


\section{Further Work}

Further work would be required to provide a similar analysis at regional level. The above analysis shows that producing regional mortality rates by year for each of the seven NS-SEC analytic classes would not be viable. However, the possibilities of providing rates and measures of inequality based on the three-class version of NS-SEC amalgamated over two or three-year periods should be examined.

All the analysis presented in this article has been of mortality in men. Census-based estimates have been produced for women by Langford and Johnson (2009). They used a 'combined' classification whereby the 'most advantaged' NS-SEC of the woman and her husband (if she has one) is used to represent the socio-economic position of the household. To produce estimates using this 'combined' classification based on LFS it would be necessary to link data for women to their husband's data, if such a person existed. This process is not straightforward, but is possible, and hence the methodology above could be extended to provide mortality rates by NS-SEC for women.

\section{Conclusions}

The results presented in this article suggest that annual trends of inequalities in mortality for men at the national level can be effectively monitored using LFS-based measures. These measures are based on the socio-economic position of the individual and would complement the use of indicators based on geographic area of residence, such as those based on the Spearhead local authorities.

The results show that there has been a steady decrease in mortality rates for all NS-SEC classes over the period 2001-08. In particular, the 'Routine' class had a decline in mortality rate almost double that of the 'Higher managerial and professional' class.

A number of different indicators were examined, both absolute and relative, and all showed a similar pattern of declining absolute inequalities but rising relative inequalities. This effect was observed when using simple ratios or differences, and when using more complex model-based measures of inequality. It is recommended that, for the sake of simplicity, differences or ratios based on the three-class NS-SEC schema are used as annual headline measures, but that conclusions drawn from these are checked against the more complex model-based measures.

The results show that over the period 2001-08 there has been a small decline in the absolute gap between the mortality rate of the 'Managerial and professional class' and the 'Routine and manual' class. (The gap was 233 deaths per 100,000 in 2001, and 229 deaths per 100,000 in 2008). However, when relative measures were used there was some evidence that inequalities had risen over the same period. In 2001 those in the 'Routine and manual' class had a mortality rate 2.0 times that of those in the 'Managerial and professional' class. In 2008 the same ratio was statistically significantly higher at 2.3 .

The absolute gap between the mortality rate of those in the 'Higher managerial and professional' class and the 'Routine' class declined from 387 deaths per 100,000 to 339 deaths per 100,000 in 2001-08. However, the mortality ratio between the two classes increased from 3.2 to 3.5 over the same period. 
The pattern of declining absolute inequalities but rising relative inequalities is a well-known phenomenon in the context of declining overall mortality rates. Many authors suggest that both absolute and relative measures should be used to assess inequalities. The results reported here could be used as a basis for high-level indicators of the trend in health inequalities, but not for localised performance targets. 


\section{References}

The Acheson Report (1998) Independent Inquiry into Inequalities in Health, TSO:London

Barnes W, Bright G and Hewat C (2008) 'Making sense of Labour Force Survey response rates', Economic and Labour Market Review 2(12) pp 32-41

Bartley M (2004) Health Inequality: an introduction to theories, concepts and methods, Polity Press: Cambridge

The Black Report (1992) in Townsend P and Davidson N (eds) Inequalities in Health. The Black Report and The Health Divide. Penguin Books, London

Blane D, Davey Smith G and Bartley M (1993) 'Social selection - what does it contribute to social class differences in health', Sociology of health and illness 15 pp 2-15.

Bostrom G and Rosen M (2003) 'Measuring social inequalities in health - politics or science?' Scandanavian Journal of Public Health 31 pp 211-215

Davey Smith G, Dorling D, Mitchell R and Shaw M (2002) 'Health inequalities in Britain: continuing increases up to the end of the $20^{\text {th }}$ century' Journal of Epidemiol Community Health 56 pp 434-435

Department of Health (2003) Tackling Health Inequalities: A programme for action, Department of Health: London.

Department of Health (2009) Tackling Health Inequalities:2006-08 Policy and Data Update for the 2010 National Target, Department of Health: London.

Drever F and Bunting J (1997)'Patterns and trends in male mortality' in Drever F and Whitehead M (eds), Health Inequalities, London:TSO

Eikemo T, Skalicka V and Avendano M (2009) 'Variations in relative health inequalities: are they a mathematical artefact?' International Journal for Equity in Health 8:32

Fox A, Goldblatt P O and Jones D (1985) 'Social class mortality differentials: artefact, selection or life circumstances?', Journal of Epidemiology and Community Health 39 pp 01-08.

Fryers $\mathrm{P}$ (2009) 'Technical issues in measuring and monitoring targets to reduce health inequalities' in The Marmot Review (2010) Post-2010 strategic review of health inequalities (The Marmot Review), The Marmot Review, London.

Houweling T, Kunst A E, Huisman M and Mackenbach J P (2007) 'Using relative and absolute measures for monitoring health inequalities: experiences from cross-national analyses on maternal and child health', International Journal for Equity in Health 6:15

Johnson B and Langford A (2010) 'Intercensal denominators-feasibility of using the Labour Force Survey to estimate mortality rates by NS-SEC' , Health Statistics Quarterly 45 pp 3-27 
Langford A and Johnson B (2009) 'Social inequalities in adult female mortality by the National Statistics Socio-economic Classification, England and Wales, 2001-03', Health Statistics Quarterly 42 pp 6-21

Mackenbach J P and Kunst A E (1997) 'Measuring the magnitude of socio-economic inequalities in health: an overview of available measures illustrated with two examples from Europe', Soc Sci Med 44(6) pp 757-771

The Marmot Review (2010) Post-2010 strategic review of health inequalities (The Marmot Review), The Marmot Review, London.

Mustard C A and Etches J (2003) 'Gender differences in socio-economic inequality in mortality', Journal of Epidemiology and Community Health 57 pp 974-980.

Office for National Statistics (2007) The National Statistics Socio-economic Classification online edition. Available on the Office for National Statistics website:

www.statistics.gov.uk/statbase/Product.asp?vlnk=13561

Office for National Statistics (2007) Trends in ONS Longitudinal Study estimates of life expectancy, by social class 1972-2005. Available on the Office for National Statistics website:

www.statistics.gov.uk/statbase/Product.asp?vlnk $=8460$

Office for National Statistics (2009) The Labour Force Survey User Guide Volume 1 Background and Methodology. Available on the Office for National Statistics website:

www.statistics.gov.uk/statbase/Product.asp?vlnk=1537

Rose D and Pevalin D (Eds) (2003) A Researcher's Guide to the National Statistics Socioeconomic Classification. SAGE Publications Ltd.

Scanlan J P (2000) 'Race and Mortality', Society 37(2) pp 29-35

Sergeant J and Firth D (2006) 'Relative index of inequality: definition, estimation and inference' Biostatistics 7:2 pp 213-224

Thomas M and Aubrey-Smith S (2008) 'The impact of Labour Force Survey and Annual Population Survey reweighting' Economic and Labour Market Review 2(12) pp 56-63

Victora C G, Vaughan J P, Barros F C, Silva A C and Tomasi E (2000) 'Explaining trends in inequities: evidence from Brazilian child health studies', The Lancet 356 pp 1093-1098

Wagstaff A, Paci P and van Doorslaer E (1991) 'On the measurement of inequalities in health', Soc Sci Med 33 pp 545-57

White C, van Gelen F and Chow Y H (2003) 'Trends in social class differences in mortality by cause, 1986 to 2000', Health Statistics Quarterly 20 pp 25-37 
White C, Glickman M, Johnson B and Corbin T (2007) 'Social inequalities in adult male mortality by the National Statistics Socio-Economic Classification, England and Wales, 2001-03', Health Statistics Quarterly 36 pp 6-23 Available on the Office for National Statistics website: www.statistics.gov.uk/cci/article.asp?id=1901 